\title{
Penerapan Media Pembelajaran Interaktif Kearifan Lokal Kabupaten Semarang
}

\author{
Swantyka Ilham Prahesti ${ }^{1 凶}$, Syifa Fauziah $^{2}$ \\ Pendidikan Guru Pendidikan Anak Usia Dini, Universitas Ngudi Waluyo, Indonesia $(1,2)$ \\ DOI: $10.31004 /$ obsesi.v6i1.879
}

\begin{abstract}
Abstrak
Anak usia dini memerlukan banyak sekali informasi untuk mengisi pengetahuannya agar siap menjadi manusia sesungguhnya. Dalam hal ini memberikan pengetahuan tentang kearifan lokal di setiap daerah kepada anak-anak. Penelitian ini secara umum bertujuan untuk meneliti dan mengembangkan suatu media pembelajaran. Secara khusus penelitian ini bertujuan untuk menentukan hasil pencapaian pengetahuan menggunakan media pembelajaran interaktif dan media konvensional. Metode penelitian yang digunakan dalam penelitian ini adalah menggunakan metode kuantitatif. Desain penelitian ini menggunakan quasi group design. Hasil dan pembahasan dalam penelitian ini dapat ditarik kesimpulan bahwa hasil pencapaian media pembelajaran interaktif kearifan lokal kabupaten semarang menggunakan video animasi lebih besar dari pada hasil pencapaian media pembelajaran interaktif kearifan lokal kabupaten semarang menggunakan video konvensional. Saran dalam penelitian ini yaitu dapat melakukan penelitian lanjutan terkait Media Pembelajaran Interaktif Kearifan Lokal Kabupaten Semarang dengan menggunakan tema atau daerah lainnya.
\end{abstract}

Kata Kunci: media pembelajaran; interaktif; kearifan lokal.

\begin{abstract}
Early childhood requires a lot of information to fill their knowledge so that they are ready to become real humans. In this case, providing knowledge about local wisdom in each area to children. This research generally aims to research and develop a learning media. Specifically, this study aims to determine the results of knowledge attainment using interactive learning media and conventional media. The research method used in this research is to use quantitative methods. This research design uses a quasi group design. The results and discussion in this study can be concluded that the results of the achievement of interactive learning media of local wisdom of Semarang district using animated videos are greater than the results of the achievement of interactive learning media of local wisdom of Semarang district using conventional videos. Suggestions in this study are to conduct further research related to the Interactive Learning Media of Local Wisdom in Semarang Regency by using themes or other areas.
\end{abstract}

Keywords: learning media; interactive; local wisdom.

Copyright (c) 2021 Swantyka Ilham Prahesti, Syifa Fauziah

$\triangle$ Corresponding author :

Email Address : swantyka05@gmail.com ( Jl. Diponegoro 186 Ungaran Barat, Kab. Semarang )

Received 6 November 2020, Accepted 31 May 2021, Published 6 Juni 2021 


\section{PENDAHULUAN}

Pendidikan memiliki tujuan umum yaitu memberikan fasilitas lingkungan yang memungkinkan anak didik dapat mengembangkan kreatifitas meliputi bakat dan kemampuannya secara optimal, supaya anak usia dini dapat menciptakan dan berfungsi sepenuhnya, sesuai dengan kebutuhan pribadinya dan kebutuhan masyarakat. Setiap anak memiliki bakat dan kemampuan yang berbeda-beda pula. Sehingga, Sistem pendidikan nasional dalam batas tertentu telah menghasilkan insan yang berkualitas, misalnya sejumlah orang yang dipercaya untuk menduduki posisi strategis di semua sektor dan di tengah-tengah masyarakat (Suyitno, 2012).

Anak Usia Dini memiliki masa peka yang merupakan masa terjadinya pematangan fungsi-fungsi fisik dan psikis yang siap merespon rangsangan yang diberikan oleh lingkungan. Anak Usia Dini dalam mengembangkan kreativitas tidak serta merta menggunakan lembar kerja yang selalu menilai aspek kognitif dan aspek bahasa saja, melainkan sebuah metode yang dapat digunakan untuk menilai aktivitas kesenian. Banyak sekali kegiatan yang lembaga PAUD sajikan, namun belum cukup untuk mengembangkan kreativitas anak, karena dalam mengembangkan kreativitas anak dibutuhkan sebuah metode untuk membangun kreativitas anak.

Anak usia dini memerlukan banyak sekali informasi untuk mengisi pengetahuannya agar siap menjadi manusia sesungguhnya. Sehingga perlunya fasilitas media pembelajaran untuk memberikan informasi atau memberikan pengetahuan yang mereka butuhkan. Para pengajar berinovasi dalam berbagai aspek penyelenggaraan pendidikan, baik itu metode, media dan pengembangan teknologi informasi untuk meminimalisir permasalahan dengan menciptakan pembelajaran yang efektif (Fauziddin et al., 2021). Media pembelajaran interaktif tentang kearifan lokal diperlukan untuk menumbuhkan pengetahuan anak usia dini. Tujuannya yaitu memberikan sebuah informasi atau sebuah pengetahuan kepada Anak Usia Dini terkait kearifan lokal yang ada di Kabupaten Semarang. Sartini (2004) mendefinisikan bahwa kearifan lokal merupakan gagasan setempat (lokal) yang bersifat bijaksana, penuh kearifan, bernilai baik yang tertanam dan diikuti oleh anggota masyarakat. Pengintegrasian kearifan lokal dalam pembelajaran sebagai untuk meningkatkan rasa cinta kearifan lokal dilingkungannya serta sebagai upaya menjaga eksistensi kearifan lokal ditengah derasnya arus globalisasi (Faela, 2018). Menurut Munawar et al. (2013) pembelajaran inovatif merupakan bentuk pembelajaran yang menarik, menyenangkan, dan dapat memfasilitasi perkembangan dan kebutuhan anak khususnya di Paud. Selain itu menurut Wulansari (2017) Seni Budaya bertujuan memahami seni dalam konteks ilmu pengetahuan, teknologi, dan sosial sehingga dapat berperan dalam perkembangan sejarah peradaban dan kebudayaan, baik dalam tingkat lokal, nasional, regional, maupun global. Ferdianto \& Setiyani (2018) menyebutkan bahwa salah satu upaya yang dapat dilakukan memasukkan nilai-nilai kearifan lokal adalah dengan cara merancang, membuat dan mengembangkan bahan ajar berbasis nilai kearifan lokal. Sementara itu menurut Sularso (2016) menyebutkan bahwa proses pendidikan dengan menjadikan kearifan lokal penting untuk direalisasikan sebab kearifan lokal sudah mulai terabaikan yang terlihat dari perilaku kehidupan sehari-hari yang tidak mewujdukan nilai-nilai kearifan lokal dan lokalitas tergerus oleh tatanan gaya hidup yang di dalamnya mengandung nilai pragmatiskapitalistik.

Heinich (Daryanto, 2010) menyebutkan "kata media berasal dari bahasa latin dan merupakan bentuk jamak dari kata medium. Medium dapat didefinisikan sebagai perantara atau pengantar terjadinya komunikasi dsari pengirim menuju penerima." Pendapat tersebut senada dengan pengertian media menurut AECT (Daryanto, 2010) yang menyebutkan media sebagai segala bentuk dan saluran yang digunakan orang untuk menyalurkan pesan/informasi.

Media digunakan sebagai alat untuk menyampaikan pesan dari komunikator kepada komunikan. Penggunaan media akan menunjang keberhasilan penerimaan pesan secara maksimal oleh komunikan, sehingga respon yang diberikan akan berupa respon positif. 
Pendapat lain dikemukakan oleh Gagne \& Briggs (1991) yang menyebutkan bahwa "media adalah segala alat fisik yang dapat menyajikan pesan serta merangsang siswa untuk belajar." Media yang digunakan dapat berupa buku, film, kaset, film bingkai dan lain sebagainya. Pendapat tersebut juga diperkuat oleh Mirso (Daryanto, 2010: 6) yang menyatakan bahwa "media adalah segala sesuatu yang dapat digunakan untuk menyalurkan pesan yang dapat merangsang pikiran, perasaan, perhatian dan kemauan siswa untuk belajar." Makna kata media berdasarkan kedua pendapat diatas merupakan alat yang dapat digunakan untuk menyampaikan pesan dalam proses pembelajaran sehingga meningkatkan antusias siswa untuk belajar. Sedangkan multimedia pembelajaran interaktif memiliki menu-menu khusus yang dapat diakses oleh user (anak TK) untuk memunculkan informasi berupa audio, visual maupun fitur lain yang diinginkan oleh pengguna (Putra dan Ishartiwi, 2015: 170).

Febiharsa \& Djuniadi (2018) mendefinisikan media pembelajaran interaktif 3 dimensi merupakan media yang memungkinkan virtualisasi objek pembelajaran ke dalam komputer. Media merupakan komponen dalam sebuah proses komunikasi dan akan sangat menunjang keberhasilan penyampaian pesan. Media juga digunakan sebagai alat bantu dalam proses pendidikan yang dapat memberikan motivasi belajar dan meningkatkan daya serap terhadap informasi yang disampaikan. Pengertian media pembelajaran menurut (Gagne \& Briggs (1991) secara implisit mengatakan bahwa media pembelajaran meliputi alat yang secara fisik digunakan untuk menyampaikan isi materi pembelajaran yang terdiri antara lain buku, tape recorder, kaset, video, kamera, video recorder, film, slide (gambar bingkai), photo, gambar, grafik, televisi dan komputer. Penggunaan media pembelajaran pada tahap orientasi pembelajaran akan sangat membantu keaktifan pembelajaran dan penyampaian pesan dari isi pembelajaran. Sedangkan Maulida et al. (2018) menjelaskan sistem komputer menyajikan serangkaian program pengajaran kepada siswa baik berupa informasi maupun latihan soal untuk mencapai tujuan pembelajaran tertentu dan siswa melakukan aktivitas belajar dengan cara berinteraksi dengan sistem komputer.

Menurut Sudjana \& Rivai (2001), ada beberapa manfaat penggunaan media pembelajaran, yaitu: (1) Pengajaran akan lebih menarik perhatian siswa sehingga dapat menumbuhkan motivasi belajar; (2) Bahan pengajaran akan lebih jelas maknanya sehingga dapat lebih dipahami oleh siswa; (3) Metode mengajar akan lebih bervariasi. Sedangkan menurut Dewi et al. (2014) media animasi pembelajaran merupakan salah satu jenis media audio visual yang berisi kumpulan gambar yang diolah sedemikian rupa sehingga menghasilkan gerakan dan dilengkapi dengan audio sehingga berkesan hidup serta menyimpan pesan-pesan pembelajaran.

Berdasarkan beberapa pendapat di atas dapat disimpulkan bahwa media adalah alat yang dapat digunakan sebagai perantara atau pengantar pesan dari komunikator kepada komunikan, sehingga pesan akan diterima secara maksimal dan menghasilkan rangsangan atau respon positif dari penerima pesan (komunikan) sesuai dengan yang diinginkan oleh komunikator.

\section{METODOLOGI}

Metode yang digunakan dalam penelitian ini yaitu menggunakan pendekatan kuantitatif. Langkah-langkah yang digunakan dalam pengambilan data yaitu a) menentukan sampel penelitian dengan menggunakan teknik purposive sampling; b) mengambil data awal (pretes) peserta didik kelompok eksperimen1 dan kelompok eksperimen2 untuk dilakukan uji normalitas dan uji homogenitas, dengan tujuan agar kelas eksperimen1 dan kelas eksperimen2 memiliki tingkatan homogenitas dan normalitas yang sama sebelum dilakukan penelitian; c) menyusun kegiatan yang akan diteliti; d) melaksanakan kegiatan; e) menganalisis hasil pada kelompok eksperimen1 dan kelompok eksperimen2; dan f) menyusun hasil penelitian. Yang diujikan dalam penelitian ini adalah media pembelajaran interaktif. Gambar 1 Susunan Diagram Alir Penelitian. 


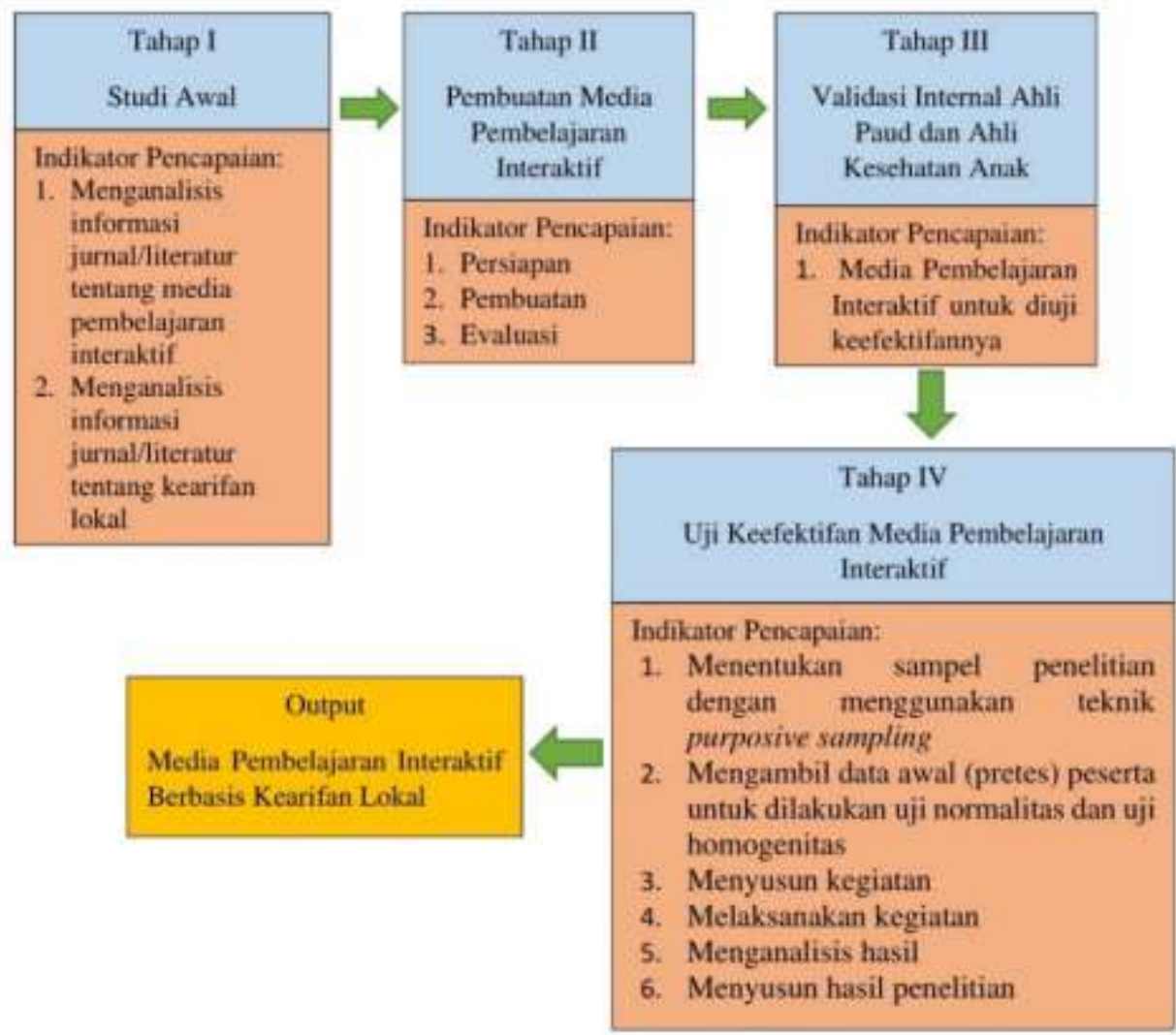

Gambar 1. Diagram Alir Penelitian

\section{HASIL DAN PEMBAHASAN}

Studi Pendahuluan

Dalam penelitian ini memerlukan studi pendahuluan yang berupa literatur, buku media pembelajaran dan online, untuk menentukan konsep atau ide dalam pembuatan animasi Media Pembelajaran Interaktif Kearifan Lokal Kabupaten Semarang.

\section{Tahapan Pembuatan Media Pembelajaran Interaktif}

Dalam pembuatan media pembelajaran interaktif ini tim peneliti membuat konsep atau story book untuk memudahkan anak usia dini memahami isi yang ada didalam media pembelajaran interaktif tersebut. Tahap-tahap pembuatan Media Pembelajaran Interaktif Kearifan Lokal Kabupaten Semarang dapat dilihat pada gambar 1 sampai 5.

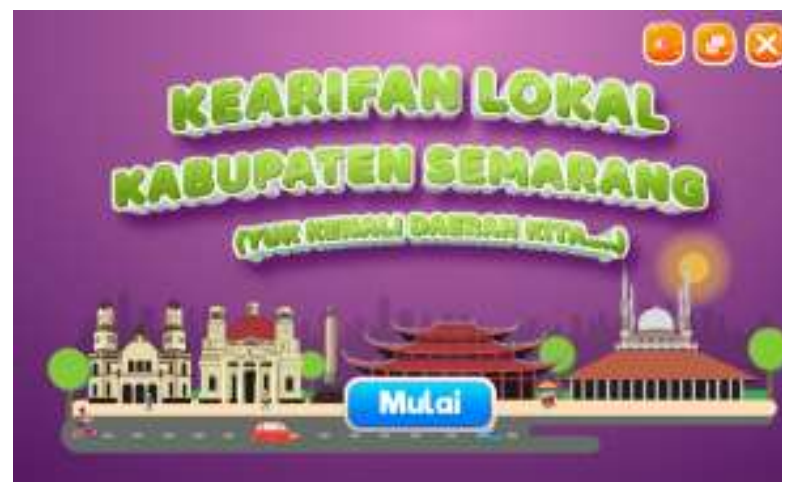

Gambar 1 Tampilan awal

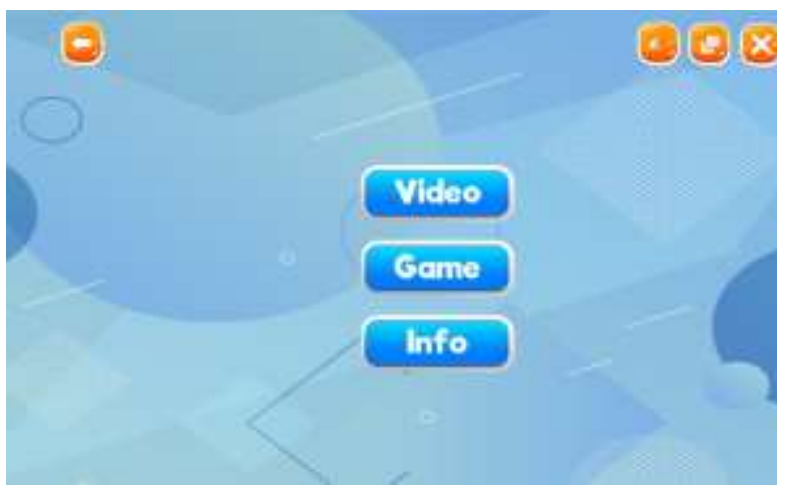

Gambar 2 Menu pilihan 


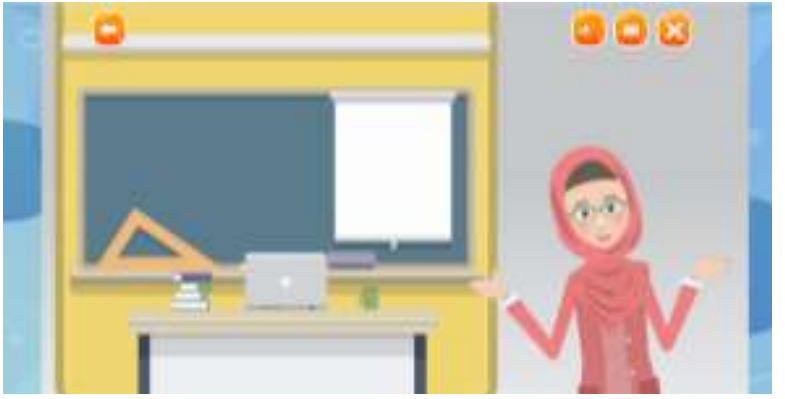

Gambar 3. Penjelasan Permainan

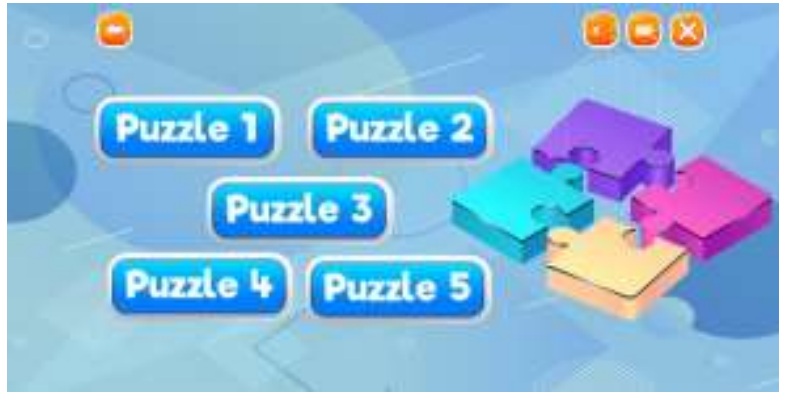

Gambar 4. Menu Permainan

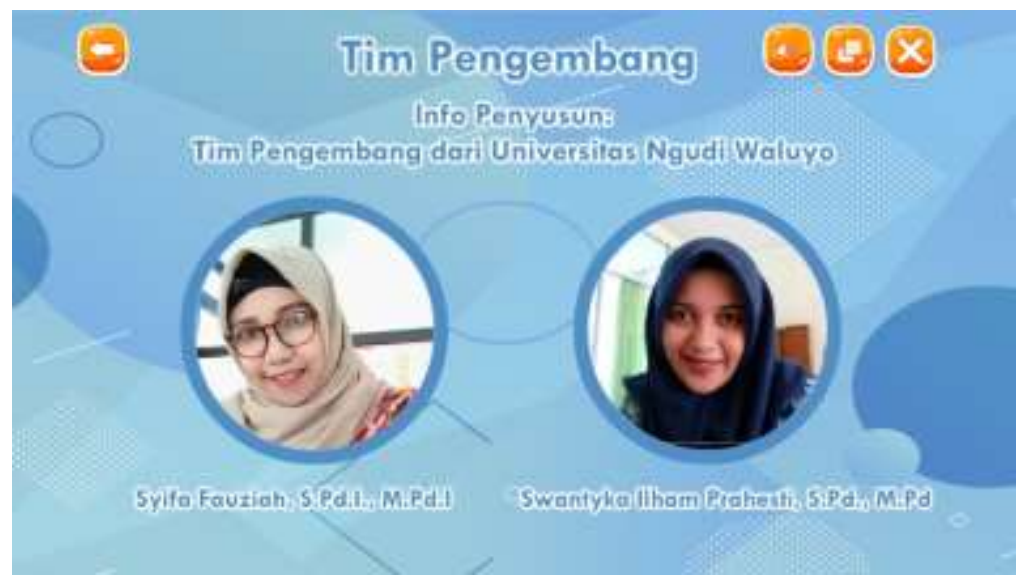

Gambar 5. Tim Pengembang

\section{Hasil akhir Media Pembelajaran Interaktif}

Uji keefektifan ini dilakukan setelah mendapatkan validasi dari validator. Berikut adalah hasil uji coba keefektifan Media Pembelajaran Interaktif Kearifan Lokal Kabupaten Semarang:

\section{Hasil Pencapaian Media Pembelajaran Interaktif Menggunakan Video Animasi Kearifan Lokal Kabupaten Semarang}

Hasil uji coba penggunaan video animasi sebelum dilaksanakan pretes memiliki ratarata tingkat kreativitas sebesar 15,45 poin. Setelah dilaksanakan perlakuan menggunakan video animasi, setelah dilakukan post test memiliki rata-rata sebesar 30,55 poin. Hasil pretest dan posttest berdasarkan kriteria dapat dilihat berdasarkan Tabel 1.

Tabel 1 Hasil Uji Paired Sample Statistics Kelompok 1

Paired Samples Statistics

\begin{tabular}{|c|c|c|c|c|}
\hline & Mean & $\mathrm{N}$ & Std. Deviation & Std. Error Mean \\
\hline Pair 1 Pretest_1 & 15.45 & 15 & 1.943 & .434 \\
\hline Posttest_1 & 18.65 & 15 & 3.501 & .782 \\
\hline
\end{tabular}

Berdasarkan Tabel 1 didapatkan bahwa nilai rata-rata pretes yang semula 15,45 mengalami perubahan menjadi 18,65, jadi kelompok 1 mengalami peningkatan sebesar 3,20.

\section{Hasil Pencapaian Media Pembelajaran Interaktif Menggunakan Video Konvensional}

Sebelum dilaksanakan kegiatan, hasil pencapaian perkembangan dengan media konvensional memiliki nilai rata-rata sebesar 18,55 poin. Setelah dilakukan kegiatan, anakanak kelompok 1 diukur lagi untuk mendapatkan kemampuan akhir. Rata-rata hasil postes anak-anak kelompok 1 sebesar 20,25 poin. Hasil pembelajaran kelompok 1 berdasarkan kriteria dapat dilihat berdasarkan Tabel 2. 
Tabel 2 Hasil Uji Paired Sample Statistics Kelompok 2

Paired Samples Statistics

\begin{tabular}{llrrrr}
\hline & & Mean & N & Std. Deviation & \multicolumn{2}{c}{ Std. Error Mean } \\
\hline Pair 1 & pretest_2 & 18.55 & 15 & 1.926 & .430 \\
& posttest_2 & 20.25 & 15 & 2.149 & .480 \\
\hline
\end{tabular}

Berdasarkan Tabel 2 nilai rata-rata pretes kelompok 2 yang semula 18,55 berubah menjadi 20,22, jadi kelompok 2 mengalami peningkatan sebesar 1,70.

\section{Perbedaan Hasil Pencapaian Media Pembelajaran Interaktif Menggunakan Video Animasi dan Video Konvensional}

Keefektifan kegiatan pembelajaran menggunakan media interaktif dapat diamati berdasarkan hasil pembelajaran maupun tercapainya tujuan pembelajaran. Hasil pembelajaran dapat dianalisis melalui hasil postes, dikarenakan hasil pretes kelompok 1 dan kelompok 2 memiliki hasil permulaan yang sama. Rata-rata hasil postes anak-anak kelompok 1 sebesar 18,65 poin, dengan besar peningkatan dari pretes menuju postes sebesar 3,20. Sementara itu hasil postes anak-anak kelompok 2 sebesar 20,25 poin, dengan besar peningkatan dari pretes menuju postes sebesar 1,70 poin. Keefektifan media pembelajaran interaktif dapat dilihat dan dianalisis berdasarkan hasil pengujian melalui output independent sample test pada Tabel 3.

Tabel 3 Hasil Uji Independent Sample Test Postes Independent Samples Test

\begin{tabular}{|c|c|c|c|c|c|c|c|c|}
\hline & & \multicolumn{3}{|c|}{$\begin{array}{l}\text { Levene's Test } \\
\text { for Equality of } \\
\text { Variances }\end{array}$} & \multicolumn{4}{|c|}{ t-test for Equality of Means } \\
\hline & & $\mathrm{F}$ & Sig. & $\mathrm{t}$ & $\mathrm{df}$ & $\begin{array}{l}\text { Sig. (2- } \\
\text { tailed) }\end{array}$ & $\begin{array}{c}\text { Mean } \\
\text { Difference }\end{array}$ & $\begin{array}{l}\text { Std. Error } \\
\text { Difference }\end{array}$ \\
\hline \multirow[t]{2}{*}{ Posttest } & $\begin{array}{l}\text { Equal variances } \\
\text { assumed }\end{array}$ & 3.480 & .067 & 9.863 & 58 & .000 & 7.600 & .77053 \\
\hline & $\begin{array}{l}\text { Equal variances } \\
\text { not assumed }\end{array}$ & & & 9.863 & 52.404 & .000 & 7.600 & .77053 \\
\hline
\end{tabular}

Secara umum, hasil penelitian ini dinyatakan bahwa penggunaan video animasi lebih efektif dalam menumbuhkan pengetahuan tentang kearifan lokal pada anak usia dini dibandingkan menggunakan media konvensional, dengan kata lain video animasi kearifan lokal memberikan pengaruh yang signifikan terhadap pengetahuan anak usia dini.

\section{Pembahasan}

Media Pembelajaran Kearifan Lokal ini merupakan inovasi pembelajaran sebagai pembelajaran yang utuh dalam aspek kognitif, afektif, dan psikomotorik. Pembelajaran menggunakan media interaktif merupakan salah satu unsur penunjang pembelajaran agar tercipta pembelajaran yang efektif. Hal itu senada dengan pendapat Dewi et al. (2014) "Media animasi pembelajaran merupakan salah satu jenis media audio visual yang berisi kumpulan gambar yang diolah sedemikian rupa sehingga menghasilkan gerakan dan dilengkapi dengan audio sehingga berkesan hidup serta menyimpan pesan-pesan pembelajaran". Lebih lanjut penelitian yang dilakukan oleh Khotimah et al. (2020) didapati bahwa media gambar dirasa lebih efektif digunakan dalam pembelajaran, hal ini dikarenakan anak sekarang lebih suka menonton film animasi yang lucu dan menarik dengan gambar yang bervariasi. Vitianingsih 
(2016) juga mendapati media animasi dapat meningkatkan daya ingat sehingga anak dapat menyimpan materi pelajaran dalam waktu yang lebih lama dibandingkan dengan metode pengajaran konvensional.

Penerapan Media Pembelajaran Interaktif Kearifan Lokal dapat meningkatkan pengetahuan peserta didik dalam mengenal budaya setempat, karena penyampaiannya melalui media pembelajaran interaktif yang dimana anak usia dini lebih menikmati dibandingkan dengan pembelajaran yang bersifat manual. Hal ini senada dengan penelitian yang dilakukan oleh Sularso (2016) menyebutkan bahwa proses pendidikan dengan menjadikan kearifan lokal penting untuk direalisasikan sebab kearifan lokal sudah mulai terabaikan yang terlihat dari perilaku kehidupan sehari-hari yang tidak mewujdukan nilainilai kearifan lokal dan lokalitas tergerus oleh tatanan gaya hidup yang di dalamnya mengandung nilai pragmatiskapitalistik. Fauziyah (2020) menyatakan bahwa media pembelajaran supaya tidak monoton dan membosankan bisa diselingi games, kuis, atau materi pembelajaran dimuat seperti vlog. Dengan demikian media pembelajaran yang digunakan berbasis kearifan lokal dan berupa game interaktif dapat lebih mengenalkan budaya lokal pada anak.

Kebaharuan dalam penelitian ini yaitu menggunakan variabel Kearifan Lokal Kabupaten Semarang. Penelitian ini tidak hanya meneliti mengenai media pembelajarannya, namun juga menggunakan variabel Kearifan Lokalnya.

\section{SIMPULAN}

Berdasarkan hasil penelitian dan pembahasan yang dilakukan tentang penggunaan media pembelajaran interaktif kearifan lokal kabupaten semarang melalui video animasi ini, maka dapat ditarik kesimpulan bahwa hasil pencapaian media pembelajaran interaktif kearifan lokal kabupaten semarang menggunakan video animasi lebih besar dari pada hasil pencapaian media pembelajaran interaktif kearifan lokal kabupaten semarang menggunakan video konvensional dibuktikan melalui uji $\mathrm{t}$ Independent bahwa data postes antara kelompok 1 dan kelompok 2 adalah $\mathrm{H}_{0}$ ditolak karena memiliki nilai $t_{\text {hitung }}=9,863$ dengan $t_{\text {tabel }}=-2,048$.

\section{UCAPAN TERIMA KASIH}

Penelitian ini mendapatkan hibah dikti dengan skim penelitian dosen pemula. Penulis mengucapkan terima kasih atas diperolehnya hibah dikti ini untuk memperlancar proses penelitian dengan judul "Media Pembelajaran Interaktif Kearifan Lokal Kabupaten Semarang". Penulis juga menyampaikan ucapan terima kasihnya kepada pengelola jurnal Obsesi yang telah memberikan kesempatan penulis menerbitkan artikel hasil penelitian yang di danai oleh dikti.

\section{DAFTAR PUSTAKA}

Daryanto. (2010). Media Pembelajaran Perananya Sangat Penting Dalam Mencapai Tujuan Pembelajaran. Gava Media.

Dewi, N. M. O., Wirya, N., Asril, N. M., \& Psi, S. (2014). Penerapan Metode Bermain Berbantuan Media Balok Cruissenare Untuk Meningkatkan Perkembangan Kognitif Pada Anak Usia Dini. Jurnal Pendidikan Anak Usia Dini Undiksha, 2(1). https://doi.org/10.23887/paud.v2i1.2982

Faela, S. N. K. (2018). Pembelajaran Berbasis Kearifan Lokal Di Sekolah Dasar: Sebuah Kerangka Konseptual. Inopendas Jurnal Ilmiah Kependidikan, 1(1), 48-53. https://doi.org/10.24176/jino.v1i1.2316

Fauziddin, M., Mayasari, D., \& Rizki, L. M. (2021). Effective Learning for Early Childhood during Global Pandemic. Al-Ishlah: Jurnal Pendidikan, 13(1).

Fauziyah, N. (2020). Dampak Covid-19 Terhadap Efektivitas Pembelajaran Daring Pendidikan Islam. Al-Mau'Izhoh, 2(2), 1-11. https://doi.org/10.31004/edukatif.v2i1.89 
Febiharsa, D., \& Djuniadi, D. (2018). Pengembangan Media Pembelajaran Interaktif 3 Dimensi untuk Pembelajaran Materi Pengenalan Lingkungan Pada Anak Usia Dini di Indonesia. Journal of Studies in Early Childhood Education (J-SECE), 1(1), 75. https:// doi.org/10.31331/sece.v1i1.590

Ferdianto, F., \& Setiyani, S. (2018). Pengembangan Bahan Ajar Media Pembelajaran Berbasis Kearifan Lokal Mahasiswa Pendidikan Matematika. In JNPM (Jurnal Nasional

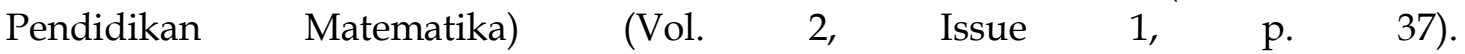
https:// doi.org/10.33603/jnpm.v2i1.781

Gagne, R. M., \& Briggs, L. J. (1991). Priniples of instructional design; Applications and illustrations. In Educational Technology. Richard and Winston.

Khotimah, S. H., Sunaryati, T., \& Suhartini, S. (2020). Penerapan Media Gambar Sebagai Upaya dalam Peningkatan Konsentrasi Belajar Anak Usia Dini. Jurnal Obsesi: Jurnal Pendidikan Anak Usia Dini, 5(1), 676. https:// doi.org/10.31004/obsesi.v5i1.683

Maulida, N., Anra, H., \& Pratiwi, H. S. (2018). Aplikasi Pembelajaran Interaktif Pengenalan Hewan pada Anak Usia Dini. Jurnal Sistem Dan Teknologi Informasi (JustIN), 6(1), 26. https://doi.org/10.26418/justin.v6i1.23726

Munawar, M., Prasetyo, A., \& Pusari, R. W. (2013). Pengembangan Model Pembelajaran Inovatif Melalui Pendekatan In House Training Berbasis Kearifan Budaya Lokal. Jurnal $\begin{array}{lll}\text { Penelitian } & \text { PAUDIA, 2(1), 1-13. }\end{array}$ download.portalgaruda.org/ article.php?article $=88239 \& v a l=530$

Sartini, S. (2004). Menggali kearifan lokal nusantara sebuah kajian filsafati. Jurnal Filsafat, $37(2), 111-120$.

Sudjana, N., \& Rivai, A. (2001). Media Pengajaran. Sinar Baru Algensindo.

Sularso, S. (2016). Revitalisasi Kearifan Lokal Dalam Pendidikan Dasar. JURNAL JPSD (Jurnal Pendidikan Sekolah Dasar), 2(1), 73. https://doi.org/10.26555/jpsd.v2i1.a4728

Suyitno, I. (2012). Pengembangan Pendidikan Karakter Dan Budaya Bangsa Berwawasan Kearifan Lokal. Jurnal Pendidikan Karakter, $0(1)$. https:// doi.org/10.21831/jpk.v0i1.1307

Vitianingsih, A. V. (2016). Game Edukasi Sebagai Media Pembelajaran Pendidikan Anak Usia Dini. Inform, 1(1), 1-8. https:// doi.org/10.37438/jimp.v1i1.7

Wulansari, B. Y. (2017). Pelestarian Seni Budaya Dan Permainan Tradisional Melalui Tema Kearifan Lokal Dalam Kurikulum Pendidikan Anak Usia Dini. Jurnal INDRIA (Jurnal Ilmiah Pendidikan Prasekolah Dan Sekolah Awal), 2(1), 1-11. https://doi.org/10.24269/jin.v2n1.2017.pp1-11 